\title{
Inovatividade e Desempenho em Microcervejarias Artesanais
}

Gabriela Do Valle Rodrigues ${ }^{1}$

Victor Silva Corrêa ${ }^{2}$

${ }^{1}$ Pontifícia Universidade Católica de Minas Gerais - PUC Minas

2 Universidade Paulista 


\section{INOVATIVIDADE E DESEMPENHO EM MICROCERVEJARIAS ARTESANAIS}

\section{Resumo}

O segmento das microcervejarias artesanais no Brasil vem crescendo exponencialmente, investindo em equipamentos modernos, matérias primas inovadoras e lançando novos produtos. Enquanto algumas empresas se saem muito bem, outras não demonstram o mesmo desempenho. O presente trabalho aí se situa, ao procurar verificar se o desempenho (financeiro e não financeiro) das empresas encontra-se associado à sua inovatividade, aqui entendida como o conjunto de iniciativas voltadas à inovação (de produtos, processos e mercado) e aos seus antecedentes dentro da empresa (foco no cliente, aprendizado e redes de relacionamento). Para isso, é elaborado um modelo teórico de análise, depois testado em quatro microcervejarias artesanais, localizadas na Região Metropolitana de Belo Horizonte. Os resultados demonstram que existe uma interação dinâmica entre inovatividade e desempenho. Ou seja, à medida que a inovatividade influencia certos tipos de desempenho, o desempenho também mostra-se capaz de influenciar algumas dimensões da inovatividade.

Palavras-chave: Inovação. Inovatividade. Desempenho. Microcervejaria artesanal.

\section{Introdução}

Existem atualmente no Brasil 889 cervejarias registradas (MAPA 2019). Os estados de Rio Grande do Sul e São Paulo lideram o ranking nacional, com 186 e 165 cervejarias, respectivamente. Minas Gerais, por sua vez, tornou-se grande destaque no setor, ultrapassando em 2018 Santa Catarina, e transformando-se no terceiro estado em número de cervejarias, 115 unidades. Cerca de 50\% delas estão concentradas na Região Metropolitana de Belo Horizonte - RMBH (CERVBRASIL 2018), onde se encontram fabricantes como a Krug Bier, a Baker Artesanal, a Walls, dentre outras, que produzem cervejas reconhecidas dentro e fora do país, apesar de serem regionais. Convivem, ao lado deles, nano cervejarias e inúmeros cervejeiros caseiros (Ferreira, Vasconcelos, Judice \& Neves 2011), muitos deles organizados geograficamente próximos. Essas empresas vêm resistindo, bravamente, aos impactos da recente crise econômica que afetou o país e, diferentemente de outros setores, que tiveram que reduzir produção e emprego, elas vêm ampliando atividades e diversificando mercados.

As expectativas são muito positivas para o segmento como um todo. Segundo dados da Associação Brasileira da Indústria da Cerveja (CERVBRASIL 2018), o setor cervejeiro representa 1,6\% do PIB nacional e gera 2,7 milhões de empregos diretos, indiretos e induzidos. O segmento artesanal representa apenas $1 \%$, porém acredita-se em forte tendência de crescimento, principalmente pelo fato de os consumidores valorizarem cada vez mais as cervejas artesanais (MAPA 2019).

Apesar do visível desenvolvimento do setor nos últimos anos, observa-se que o desempenho não é o mesmo em todas as microcervejarias. Enquanto algumas têm alcançado sucesso local, nacional e até mesmo internacional, inclusive ganhando prêmios importantes que promovem a marca e corroboram a qualidade de seus produtos, outras não conseguem a mesma performance (Vasconcelos 2017). A literatura sugere que o desempenho de uma empresa, em geral, poderia estar associado à sua capacidade de inovação (Knowles, Hansen \& 
Shook 2008; Lin, Peng \& Kao 2008; Gunday, Ulusoy, Kilic, \& Alpkan 2011; Rubera \& Kirca 2012, Veit 2014; Lee, Lee, \& Garrett 2017). No segmento específico de micro e pequenas empresas, mais próximo do universo aqui de interesse, também é possível encontrar literatura que busca associar inovação com desempenho (Acs \& Audretsch 1990; Lin \& Chen 2007; Rosli \& Sidek 2013).

Quando chegamos ao segmento de cervejas, como um todo, observa-se que não existe, no Brasil, muita literatura disponível. Na maior parte das vezes, indicadores e publicações tendem a agrupar a indústria de bebidas (em geral) com a de alimentos, alegando que são consideradas indústrias próximas, já que ambas se destinam à nutrição humana. Esse agrupamento tende a mascarar alguns indicadores e diferenças entre os setores, pois o de alimentos chega a ser oito vezes maior que o de bebidas (Ferreira et al. 2011). Ao mesmo tempo, como salientado pelo autor, quando se trata do mercado de cervejarias, as pesquisas são limitadas, em particular, no segmento das microcervejarias artesanais.

Os artigos sobre o mercado de cervejas artesanais no Brasil pontuam sobre aspectos específicos, como: a utilização da mídia social por uma cervejaria artesanal (Lima, Neto, \& Carvalho 2013), o comportamento do consumidor da microcervejaria Heilige, localizada no Rio Grande do Sul (Constantin, Abitch, \& Ceolin 2013), a análise estratégica para implantação de uma microcervejaria (Kalnin, Filho, \& Castro 2002) e as vantagens competitivas das cervejas artesanais em comparação com as grandes cervejarias (Stefenon 2012). No caso específico da RMBH, situam-se estudos de Nery (2017), que explorou o ponto de vista do consumidor e da cultura do consumo; e de Ferreira et al. (2011), sobre processos de inovação na fabricação de cervejas artesanais, sem, contudo, associá-los ao desempenho.

Nesse contexto, situa-se o presente trabalho, que tem como objetivo investigar a relação existente entre inovatividade e desempenho, pesquisando microcervejarias artesanais, localizadas na Região Metropolitana de Belo Horizonte (RMBH), estado de Minas Gerais (Brasil). O conceito de inovatividade, mais abrangente que o conceito específico de inovação, abarca, em seu bojo, também o conceito de inovação, e vem sendo consagrado na literatura (Damanpour 1991; Hult et al. 2004; Veit 2014). Enquanto inovação descreve a introdução de novos produtos, processos, sistemas de marketing e estruturas organizacionais (Schumpeter 1988; Damanpour 1991; Calantone, Cavusgil, \& Zhao 2001; Prajogo \& Ahmed 2006); inovatividade, por sua vez, engloba, além disso, também os processos empresariais por trás da inovação, tais como: capacitação de funcionários, avaliação constante das necessidades dos clientes, cooperação entre empresas, planejamento e gestão da criatividade (Hult et al. 2004; Knowles et al. 2008). Dessa maneira, entende-se por inovatividade a soma tanto dos processos empresariais que antecedem e deflagram a inovação, quanto a inovação propriamente dita, o que nos parece ideal inclusive para análise de unidades produtivas muito pequenas, dotadas de processos internos menos especializados e formalizados.

Para análise de desempenho, utiliza-se aqui tanto o desempenho financeiro, amplamente explorado na literatura (Calantone et al. 2001; Richard, Devinney, Yip \& Johnson 2009; Rosli \& Sidek 2013), quanto os não financeiros (Garrigós-Simón \& Marqués 2004; Lin et al. 2008; Lee et al. 2017).O artigo divide-se em três partes. Na primeira (referencial teórico), enfoca-se, por um lado, o tema da inovação e da inovatividade, e, por outro, o tema do desempenho, concluindo com a elaboração de modelo analítico para análise do fenômeno de interesse. A segunda parte (metodologia e resultados) apresenta os resultados da investigação empírica realizada junto a quatro microcervejarias localizadas na Região Metropolitana de Belo Horizonte (RMBH). Na terceira (Conclusão), analisa-se a adequação 
do modelo apresentado, tecendo considerações sobre as novidades da pesquisa. Os resultados demonstram que existe uma interação dinâmica entre inovatividade e desempenho. Ou seja, à medida que a inovatividade influencia certos tipos de desempenho, o desempenho também mostra-se capaz de influenciar a inovatividade.

\section{Referencial teórico e elaboração do modelo de análise}

A inovação tem sido um fator dominante para manter a competitividade em nível mundial. Ela alimenta o crescimento organizacional, impulsiona o sucesso futuro e é o motor que permite as empresas sustentarem sua viabilidade em uma economia global (Gaynor 2002). Para as empresas que buscam a excelência na era da hipercompetição, reduzir os custos e melhorar a qualidade do produto ou serviço não é mais o suficiente (Lin \& Chen 2007).

De acordo com Schumpeter (1988), há basicamente cinco tipos de inovações: 1) o lançamento de novo produto; 2) a descoberta de novos métodos de produção; 3) a abertura de novos mercados no país ou no exterior; 4) a conquista de novas fontes de suprimento de insumos; e 5) a instalação de novas formas de organização do mercado, como um novo monopólio ou a fragmentação de uma posição de monopólio. Consistente com Schumpeter (1988), outros autores também conceituaram inovação como uma ideia que tenha sido levada adiante, uma invenção disponibilizada ao consumo em larga escala (Artz, Norman, Hatfield \& Cardinal 2010).

De acordo com o grau de novidade envolvido, as inovações podem ser classificadas como radical ou incremental. Enquanto a inovação radical, associada a novas combinações de produtos e recursos, é capaz de ampliar as fronteiras de possibilidades econômicas, a incremental, que se constitui em rotina no mundo dos negócios, seria resultante de pequenos aperfeiçoamentos nos produtos, processos ou serviços, que melhoram o desempenho da empresa, e podem, eventualmente, serem perceptíveis aos consumidores (Tidd \& Bessant 2008).

Muitos autores ainda compartilham a visão de Schumpeter (1988) que considerava que nas grandes empresas haveria um loco mais adequado para o exercício da inovação (Brasil, Nogueira \& Forte 2011; Damanpour 1991). Se opondo a essa visão, (Acs \& Audretsch 1990) argumenta que quanto menor o tamanho da empresa, mais inovadora ela será, pois pequenas empresas crescem e se desenvolvem continuamente por meio da inovação. $\mathrm{O}$ autor constatou em seu estudo que as ações voltadas para a inovação contribuem para o crescimento do negócio e que os proprietários procuram desenvolver pequenas novidades constantemente, a fim de manterem a competitividade do negócio e garantir a lucratividade. As vantagens das pequenas empresas em relação às grandes seriam a sua flexibilidade e velocidade de resposta.

Para Lin e Chen (2007), as pequenas empresas não realizam inovações geradas por $\mathrm{P} \& \mathrm{D}$, como as grandes empresas. Normalmente, elas têm seu negócio ligado à linha de produção e inovam em atividades relacionadas com a adaptação de tecnologias adquiridas, ou em pequenas melhorias implementadas na fábrica. Segundo Robertson, Casali e Jacobson (2012), a criação de um ambiente inovador integrado e dinâmico para as PMEs depende principalmente de modificações em seu processo, tendo em vista esse ser o responsável por mudanças que afetam desde a criação da ideia até seu desenvolvimento e lançamento como inovação. Destacam ainda que o potencial competitivo dessas empresas pode ser melhorado pela inserção de práticas as quais permitam a elas inovarem de maneira competitiva.

Diferentes pesquisas sobre capacidade inovadora das empresas, tanto em grandes, quanto em pequenas, vêm, mais recentemente, utilizando o constructo inovatividade. Bakar e Ahmad 
(2010) consideram a inovatividade como uma perspectiva que vai além da inovação de produtos, destacando a importância de fatores subjacentes, como mudanças comportamentais, a inovação de processos e a orientação estratégica para a inovação. Quandt, Ferraresi, e Bezerra (2013) destacam que o conceito de inovatividade refere-se à propensão ou à capacidade da empresa de inovar ou a sua abertura à implementação de novas ideias. Prajogo e Ahmed (2006) utilizaram uma abordagem semelhante. No trabalho dos autores, a inovatividade organizacional foi entendida como a integração entre os aspectos humanos (liderança, gestão de pessoas, gestão do conhecimento, gestão da criatividade) e os aspectos tecnológicos (gestão tecnológica e gestão de $\mathrm{P} \& \mathrm{D}$ ).

Para Knowles et al. (2008), enquanto a inovação significa um novo processo, produto, serviço ou sistema de negócios, a inovatividade consiste na inclinação a criá-los. A inovatividade encontra-se presente no ambiente organizacional, na cultura da firma, e é capaz de viabilizar maior conjunto de inovações (Hult et al. 2004). Segundo Damanpour (1991), a inovatividade de uma organização é mais satisfatoriamente representada pelo conceito de múltiplas inovações.

De acordo com Slater e Narver (1995) e Hult et al. (2004), a inovatividade demonstra a abertura da empresa a novas ideias, indicando uma propensão para a inovação. Os autores argumentam que existem antecedentes para a inovação, que seriam características inerentes ao ambiente organizacional da firma, tais como: i) foco no cliente com o objetivo de antecipar suas necessidades e responder rapidamente; e ii) compromisso com aprendizagem, que indica a apreciação e desejo de assimilar novas habilidades e ideias.

O conceito de inovatividade, ao incluir tanto os antecedentes da inovação (a exemplo da capacidade de aprender, de cooperar, de se preocupar com o cliente, etc.), como a inovação propriamente dita (seja de processo, produto, gestão, novos mercados, etc.), melhor sinalizaria a capacidade de inovação da empresa, mostrando sua habilidade em adotar ou implementar, com sucesso, novas ideias, processos ou produtos. Dessa maneira, a maior ou menor capacidade ou propensão para inovar, como característica distintiva de cada empresa, poderia influenciar e, ao mesmo tempo, ser influenciada pelo seu desempenho.

No mundo dos negócios, o sucesso encontra-se associado a desempenho. O desempenho é a variável dependente final de interesse para pesquisadores preocupados com praticamente qualquer área da gestão. Marketing, operações, recursos humanos e estratégia são, em última análise, julgados por sua contribuição para o desempenho. A medição é essencial para permitir que pesquisadores e gestores avaliem as ações específicas das empresas e gestores, onde as empresas estão com relação aos seus rivais e como as empresas evoluíram ao longo do tempo (Richard et al. 2009).

Como um constructo multidimensional, o desempenho é avaliado através de muitas dimensões, incluindo crescimento de vendas, sobrevivência, competitividade ou diminuição de custos. Na pesquisa de Lin et al. (2008), o desempenho do negócio foi definido como a realização dos objetivos organizacionais sobre o crescimento das vendas, rentabilidade e participação de mercado. Na aferição do desempenho, medidas não financeiras também são comuns, tais como produtividade, satisfação das partes interessadas e participação de mercado (Garrigós-Simón \& Marqués 2004).

Muitos procuraram avaliar a relação entre inovação (em alguns casos inovatividade) e desempenho. Para Lin e Chen (2007), o desempenho organizacional tende a ser o objetivo final da execução da inovação. A inovação, muito mais que uma ferramenta gerencial, algo passageiro ou modismo, é essencial para o entendimento do crescimento e da perenidade 
nas empresas. O lado positivo da inovação é fortemente associado ao crescimento (Tidd \& Bessant 2008). Novos negócios são criados a partir de novas ideias, pela geração de vantagem competitiva naquilo que a empresa pode ofertar. Bakar e Ahmad (2010) acrescentam que a capacidade de inovar em produtos e processos é crucial para uma empresa explorar novas oportunidades e ganhar vantagem competitiva.

Hult et al. (2004) estudaram a relação entre os três antecedentes (predisposição para o mercado, aprendizagem e empreendedorismo), inovação e performance, e argumentaram que os antecedentes e a inovação têm impacto significativo no desempenho do negócio, aqui medido pelo crescimento de vendas. A predisposição para o mercado está relacionada ao foco no cliente e a disposição da organização para entregar valor superior aos seus clientes de forma contínua. Predisposição para a aprendizagem refere-se ao desenvolvimento sucessivo de novos conhecimentos na empresa. Finalmente, a predisposição para o empreendedorismo engloba a procura por novas oportunidades, a colaboração com outras empresas, o uso das redes de relacionamento a fim de concretizar novos projetos e o posicionamento orientado para ações ousadas. Vale (2006) destaca a importância das redes de interação/relacionamento para se obter inovações de produtos e melhor performance.

De acordo com Rubera e Kirca (2012), a inovatividade influencia positivamente o valor da empresa. Ao reduzir a volatilidade dos fluxos de caixa, e ao manter a empresa atualizada com o que os clientes desejam, assegurando receitas futuras, a firma complementa seu portfólio de produtos com ofertas voltadas para os novos segmentos de mercado. Além disso, melhora a posição financeira, por meio de aperfeiçoamentos em processos produtivos, que tornam as empresas mais eficientes ao longo do tempo.

Os resultados da pesquisa realizada por Rosli e Sidek (2013) confirmaram a hipótese de que a inovação de produtos e a inovação de processos influenciaram o desempenho da empresa (crescimento de vendas) de forma significativa, onde o impacto da primeira era mais forte que da última. Além de consolidar a teoria existente sobre a importância da inovação para explicar a variação no desempenho da empresa, os resultados também informaram que, para as PMEs, a inovação é um fator crítico em atividades empresariais de hoje.

Baseando-se em proposições de diversos autores e considerando-se as peculiaridades do segmento produtivo de interesse, constituído por microcervejarias artesanais, propõe-se um modelo teórico de análise (Figura 1) a partir de algumas categorias básicas. No que diz respeito aos antecedentes da inovação, foram inseridos certos aspectos culturais julgados mais importantes no momento, que são: i) foco no cliente (Slater \& Narver 1995; Hult et al. 2004), ii) compromisso com a aprendizagem (Slater \& Narver 1995; Hult et al. 2004; Lin et al. 2008), e iii) redes de relacionamento e cooperação (Hult et al. 2004).

No que diz respeito à inovação, propriamente dita, foram incluídas: i) produto: compreende fatores associados a mudanças nos produtos ou linha de produtos; ii) processo: engloba os fatores sugestivos de mudança, melhorias, otimização de procedimentos de fabricação e distribuição dos produtos; iii) mercado: engloba iniciativas voltadas para o mercado, a promoção de marca e produtos, e a entrada em novos mercados e nichos, na linha citada por Schumpeter (1988) e explorada por diferentes autores (Lin \& Chen 2007; Gunday et al. 2011; Rosli \& Sidek 2013; Lee et al. 2017). As variáveis de interesse sobre desempenho foram organizadas em dois grandes grupos, financeiro e não financeiro. No financeiro foram incluídas: i) crescimento de vendas (Hult et al. 2004; Lin \& Chen 2007; Knowles et al. 2008; Rosli \& Sidek 2013); ii) otimização de custos (Prajogo \& Ahmed 2006; Gunday et al. 2011). 
No não financeiro: i) satisfação do cliente (Gunday et al. 2011; Lee et al. 2017); ii) premiação de produtos e destaque, visto que isso é relevante no segmento de cervejas artesanais (Vasconcelos 2017). Segundo Gunday et al. (2011), muitas vezes os benefícios da inovatividade no desempenho não são diretos, o que justifica a análise de aspectos não financeiros.

O modelo sugere que aspectos relacionados ao ambiente organizacional, sugestivos da propensão da empresa a inovar, e que constituem os antecedentes da inovação (foco no cliente; compromisso com a aprendizagem; redes de relacionamento e cooperação), ao mesmo tempo em que deflagram a inovação propriamente dita (produtos, processos e mercados), são por elas influenciadas. A relação de interdependência entre as variáveis do modelo pode ser também verificada na associação entre inovatividade e desempenho. Da mesma maneira que o desempenho financeiro (crescimento das vendas, otimização de custos) poderia afetar e ser afetado pelo desempenho não financeiro (premiação e destaques, satisfação do cliente), o desempenho, no geral, ao mesmo tempo em que poderia ser afetado pela inovatividade, também impactaria essa. Observa-se que Hult et al. (2004) propuseram um modelo em que as melhorias de performance da empresa, advindas da inovatividade, funcionam como feedback e reforço na relação entre inovatividade e desempenho, esse último representado pelas variáveis rentabilidade, crescimento de vendas e participação de mercado.

Figura 1 - Modelo de análise da relação entre inovatividade e desempenho

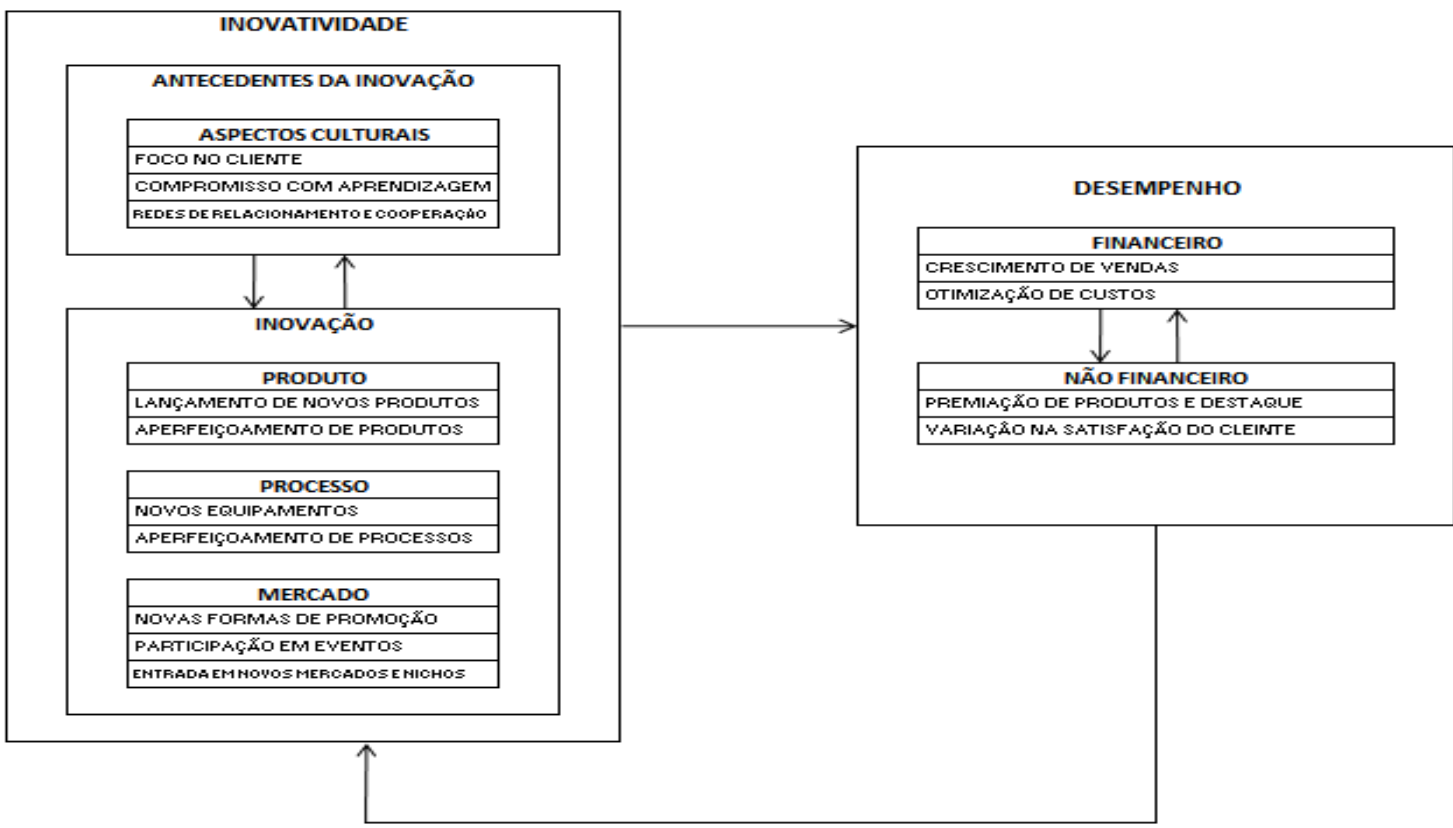

\section{Metodologia e resultados obtidos}

Fonte: Elaboração própria

Para atender os objetivos propostos nesta pesquisa, a estratégia utilizada foi a abordagem de natureza qualitativa e o método foi estudo de casos múltiplos. A pesquisa, de natureza exploratória, foi lastreada em entrevistas em profundidade realizadas junto a quatro microcervejarias artesanais (aqui designadas A, B, C e D) localizadas na Região Metropolitana de Belo Horizonte, todas com menos de 19 empregados (consideradas microempresas, segundo classificação SEBRAE). Além do critério de número de empregados, buscou-se trabalhar com empresas semelhantes também em termos do tempo no mercado, capacidade de produção e vendas. A análise dos dados foi baseada no exame, categorização e 
tabulação das evidências, atentando-se para as categorias analíticas e suas interconexões, como explicitado no modelo. A técnica de análise adotada foi a intracasos e comparações intercasos.

A empresa "A" foi fundada em 2013, através da união de três cervejarias, que passaram a dividir a mesma unidade fabril. A localização escolhida foi a cidade de Nova Lima (RMBH), polo cervejeiro do estado. Em 2016, uma das cervejarias adquiriu a parte das outras duas empresas e com novos sócios investiu na expansão da fábrica. Atualmente com 14 funcionários, a cervejaria produz no limite de sua capacidade de estocagem, 20.000 litros/mês. Contudo, as vendas giram em torno de 15.000 litros/mês. A cervejaria "B" foi fundada em 2010 por cinco amigos que são até hoje os sócios da empresa. Atualmente, dois dos sócios trabalham exclusivamente na cervejaria com o apoio de 6 funcionários. A capacidade de produção da cervejaria era de 2.000 litros/mês quando foi inaugurada em 2010. Aumentos constantes foram executados até que, em 2017, a capacidade já era de 17.000 litros/mês. A grande expansão foi realizada em 2018. Com uma nova cozinha e novos tanques de fermentação, a capacidade passou a ser de 30.000 litros. A "B" vende em média 15.000 litros/mês, o número varia e a fábrica também está localizada em Nova Lima (RMBH).

A microcervejaria "C", fundada em 2004, é uma empresa familiar que nasceu da iniciativa de três irmãos que resolveram abandonar suas atividades e investir na produção de cerveja artesanal no sítio da família em Ribeirão das Neves (RMBH). O aumento do mercado nos últimos anos permitiu duas grandes expansões da fábrica. No começo, a capacidade de produção era de 2.000 litros/mês, em 2010 passou para 10.000 litros/mês, e, desde 2015 a cervejaria está em crescimento constante, chegando à atual capacidade de 20.000 litros/mês. Durante muitos anos a "C" teve apenas 3 funcionários, atualmente são 19. Um dos sócios atua ativamente em associações e sindicatos da área e é professor em vários cursos relacionados ao mercado de cervejarias. Além disso, é sócio fundador de uma escola de sommelier de cerveja em Belo Horizonte. A "D" foi criada em 2013 e dois aspectos contribuíram para a montagem do negócio. O primeiro foi a experiência de mais de 30 anos que o fundador possuía como empresário. O outro, a fazenda onde foi instalada a fábrica, de propriedade do fundador, que já produzia outros 20 tipos de produtos, incluindo vinho e cachaça. A cervejaria está localizada em Santana dos Montes (RMBH), atualmente possui 19 funcionários e a produção de 40.000 litros/mês encontra-se no limite de capacidade da empresa.

A comparação das evidências encontradas em cada caso mostrou diferenças e semelhanças entre as empresas. O lançamento constante de produtos revela a principal similaridade, a atenção permanente às demandas dos consumidores e a busca pelo rápido atendimento dessas necessidades. Com o objetivo de atender uma das principais demandas atuais do mercado, "A" e "C" lançaram em 2018 uma cerveja estilo American Pale Ale - APA. O produto da "C" se destacou e a cervejaria ganhou um prêmio por ele num concurso no Chile. A empresa "A" ainda colocou no mercado a cerveja tipo Pilsen, de preço mais baixo e por isso mais acessível. Do ponto de vista de lançamento de produtos para atendimento ao consumidor aficionado em cerveja artesanal, a "B" se destaca ao lançar diversas versões sazonais em edições limitadas. A cervejaria " $\mathrm{D}$ " disponibiliza 22 rótulos ao consumidor e é a cervejaria com a maior linha de produtos entre as 4 analisadas.

As cervejarias " $\mathrm{C}$ " e "D" mostraram maior comprometimento com a capacitação dos funcionários, enquanto na "A" e na "B" os cursos e treinamentos acontecem de forma pontual, conforme disponibilidade, interesse e sem planejamento. A empresa "A" utilizou suas redes de relacionamento e cooperação para fazer compras coletivas e com isso obteve bons descontos na 
aquisição de mercadorias, o que contribuiu para o bom desempenho da empresa. No caso da "D", as redes favoreceram as parcerias com importantes redes de supermercado em Belo Horizonte e interior do estado. Apesar da "C" possuir extensa rede de contatos em sindicatos e associações, ela não apresentou projetos de cooperação que pudessem favorecer o desempenho da empresa. A única evidência de melhoria de desempenho resultante dela foi a conquista da inclusão das microcervejarias no Simples Nacional a partir de 2018, que apesar de ser uma importante conquista do setor não se trata de inovação. A cervejaria "B" é a que menos se beneficia das redes, mesmo estando localizada no polo cervejeiro do estado.

Todas as 4 cervejarias lançaram novos produtos em 2018. A inovação em produto consistiu no mais importante tipo de inovação exercido pelas empresas, especialmente o lançamento de novos estilos. Apenas a "A" apresentou evidência de aperfeiçoamento de produto. Um de seus produtos sofreu alteração na formulação, tornando a cerveja mais leve, palatável e ajustada ao gosto do consumidor. As cervejarias "A", "B" e "C" produzem cerveja em garrafa e chope em proporções quase iguais, priorizando o chope. A estratégia dessas empresas baseia-se em dividir o foco nesses dois tipos de produto e negócios. A "D" diferenciase neste aspecto e tem continuamente substituído a produção de chopes por cerveja engarrafada. Seu foco é a venda em supermercados, que atualmente já representam $70 \%$ de suas vendas.

As estratégias de inovação de produtos da "A" e da "B" são semelhantes, e visam o lançamento de chopes sazonais em pequena quantidade e de forma constante. Pelo fato de uma de suas cozinhas ser pequena, a "B" já conseguiu colocar o plano em prática, lançando 9 tipos de cervejas sazonais em 2018. A "A" pretende investir numa estrutura mais compacta, atualmente seu menor tanque é de 2.000 litros e não se adequa a pequenas produções. Essa estratégia, além de promover a marca, também serve de teste para possíveis lançamentos de cerveja na linha permanente. A "C" passou alguns anos sem lançar produtos até que, em 2018, disponibilizou 3 novos rótulos no mercado. A empresa planeja novos lançamentos de cervejas na sua linha permanente em 2019. Apesar da introdução de pequenas melhorias nos processos, a inovação nesse aspecto baseou-se principalmente na aquisição de novos equipamentos nas 4 cervejarias. Pequenas iniciativas foram tomadas a fim de aperfeiçoar os processos, mas os maiores resultados foram advindos da expansão na capacidade de produção.

Todas as cervejarias se dedicam a participar de eventos e feiras do setor. Quanto ao investimento em novas formas de promoção, apenas "A" e "B" contam com empresas especializadas em comunicação estratégica. Devido a isso, elas apresentaram mais evidências de esforços no aperfeiçoamento do design da marca e do site e, investimento na divulgação da empresa e de produtos nas redes sociais. Para a "A", o reflexo no desempenho parece ter sido positivo e para a "B", não, provavelmente devido ao trabalho ineficiente da área comercial. Excluindo a "B", todas as demais participaram de concursos que geraram publicidade e exposição da marca.

As cervejarias "A" e "C" tiveram um aumento importante no número de pontos de vendas em 2018. A "B" manteve o mesmo patamar e a "D" conquistou respeitáveis novos clientes, como as redes de supermercado, destacando-se uma que atende várias cidades de Minas Gerais. A cervejaria " $D$ ” é a única entre os casos estudados que já conseguiu chegar ao interior do estado. "A" e "C" tiveram um crescimento de vendas significativo em 2018, e esse resultado deve-se ao trabalho de expansão realizado nas fábricas, que em ambas foi viabilizado pela entrada de investidores. As cervejarias "B" e "D" mantiveram os mesmos patamares de vendas do ano anterior. A "B", apesar de seus esforços em lançar novos produtos e expandir sua capacidade de produção, teve retração nas vendas na maior parte do ano e apenas após uma 
recuperação no último trimestre conseguiu manter a média de 2017. A própria empresa reconhece o gargalo que sua área comercial representa. A "D" também manteve suas vendas estagnadas, porém garante que essa foi uma opção da própria empresa. A otimização de custos nas 4 empresas está relacionada aos benefícios advindos dos novos equipamentos mais tecnológicos e também aos ganhos de escala.

Apenas a "B" não obteve prêmios recentes, o que não demonstra necessariamente problemas de qualidade, pois a própria empresa optou por não enviar produtos para os concursos. $\mathrm{O}$ aumento na satisfação do cliente não pôde ser avaliado, por se tratarem de microempresas, elas ainda não possuem recursos para essa medição. Mesmo na "B" e na "D", que não obtiveram crescimento de vendas em 2018, o lançamento de produtos permitiu a entrada em novos pontos de venda.

Com relação à variável foco no cliente, cada empresa demonstrou, a seu modo, estar ligada às necessidades do consumidor. A cervejaria "A" lançou, em 2018, dois dos tipos mais demandados de cerveja artesanal atualmente, uma estilo APA, que atende os consumidores mais acostumados com as artesanais, e uma Pilsen, mais leve e barata para responder àqueles que estão entrando nesse mercado e não querem pagar caro numa cerveja. A "B" lançou 9 estilos de cerveja sazonais, satisfazendo os anseios do consumidor habituado às artesanais e sedento por novidades constantes. A "C" também disponibilizou sua versão do estilo APA, e a "D" focou sua estratégia de produção e vendas para o consumidor que deseja adquirir seus produtos em supermercados.

Uma característica importante desse mercado é o vertiginoso lançamento de produtos, e, nos 4 casos estudados, esse atributo foi detectado. Esse resultado é consistente com a proposição de Acs e Audretsch (1990). Segundo os autores, por possuírem uma estrutura menor, as pequenas empresas são mais flexíveis, e conseguem colocar suas ideias em prática com muito mais velocidade que as grandes (Acs \& Audretsch 1990). Os múltiplos lançamentos de produtos permitem ainda que a empresa desfrute do monopólio breve de cada produto que introduz (Artz et al. 2010).

Os 4 casos de cervejaria estudados não apresentaram planejamento formal de capacitação de funcionários. Porém, a "C" e a "D" demonstraram ter investido mais em profissionais capacitados e na qualificação de seus empregados. A maior suscetibilidade a investir em aprendizagem e valorização do conhecimento da "C" deve-se à aptidão advinda de um dos sócios, professor e dono de escola de especialização em sommelier de cerveja. Para obter melhores resultados em termos de inovação, as empresas precisam investir num projeto contínuo de capacitação. O compromisso com a aprendizagem é um antecedente da inovação que enfatiza o desenvolvimento contínuo de ideias e conhecimentos gerais e, que para isso, requer comprometimento e processos gerenciais (Hult et al. 2004; Lin et al. 2008).

Apesar de "C" e "D" apresentarem comprometimento com a capacitação dos funcionários, não há evidências da relação com o desempenho da empresa. Esse fato confirma a teoria de alguns autores que afirmam que o compromisso com a aprendizagem afeta positivamente a inovação, mas não diretamente o desempenho (Hult et al. 2004; Prajogo \& Ahmed 2006; Lin et al. 2008). Porém, contradiz Calantone et al. (2001), que comprova em seu estudo que essa relação é direta, e que um ambiente de aprendizagem positivo é benéfico para as empresas que aspiram se destacar através do desenvolvimento de produtos. 
Com relação às redes de relacionamento e cooperação, as cervejarias estudadas parecem não se beneficiar suficientemente daquelas construídas por elas. Segundo Vale (2006), a participação das empresas de pequeno e médio porte em redes de cooperação estimula o crescimento e a geração de inovações, possibilitando ganho coletivo. A cervejaria "C" possui uma rede extensa que inclui profissionais da área de educação e alunos, membros de sindicato e associações da área, contato com fornecedores e clientes adquiridos ao longo de seus 14 anos de história, além de donos de cervejaria em todo o Brasil e diversos países no mundo. Mesmo assim, a cervejaria não apresentou proveitos de suas redes. Em contrapartida, a "D" parece ter se beneficiado das redes de relacionamento adquiridas pelo seu sócio fundador, que também é dono de vários outros negócios e tem 34 anos de experiência como empresário. Os contatos foram importantes para a entrada de seus produtos em grandes redes de supermercados.

"A" e "B" poderiam se beneficiar mais da localização no polo cervejeiro, próximo de diversas outras fábricas. A cervejaria "A" conseguiu fazer compras coletivas de descartáveis, porém o potencial de cooperação é muito maior. A cooperação com empresas do mesmo segmento e fornecedores proporciona melhorias de produtividade, redução de riscos no desenvolvimento de produtos e reforça simultaneamente a flexibilidade, qualidade do produto e adaptabilidade ao mercado (Zeng et al. 2010).

Quanto ao desempenho financeiro, "A" e " $\mathrm{C}$ " apresentaram crescimento de vendas, por outro lado, "B" e "D" permaneceram estagnadas. O foco no cliente e o lançamento constante de produtos demonstraram papel importante nesses resultados. Exemplo disso foi a cerveja estilo Pilsen lançada pela "A" para atender a demanda do mercado e que em menos de um ano se tornou a mais vendida. Esses resultados corroboram as teorias nas quais a atenção ao mercado constitui um antecedente fundamental da inovação (Lin et al. 2008) e a inovação em produto é o tipo que causa maior impacto nas vendas (Artz et al. 2010; Rosli \& Sidek 2013).

"A" e "C" tiveram resultados semelhantes, a expansão da fábrica e os novos equipamentos repercutiram nas vendas, na entrada em novos mercados e em premiações de produtos. Esse cenário confirma a teoria de que o uso de tecnologia atual tem significativo relacionamento com o crescimento de vendas (Knowles et al. 2008; Gunday 2011; Rosli \& Sidek 2013; Lee, Lee \& Garret 2017).

A "B", apesar de também ter passado por um processo de expansão como a "A" e a "C", não conseguiu obter a mesma resposta em termos de venda. Os motivos parecem ter sido a falta de uma estrutura administrativa eficiente que seguisse a produção. A empresa reconhece que a área de vendas não acompanhou as inovações em produto e processo. Esse resultado confirma a teoria de que inovação tecnológica, sem níveis comparáveis de inovação em todos os setores da organização, reduz significativamente os benefícios de se investir em inovação (Gaynor 2002). Inovações em produto e processo que não são acompanhadas por inovações administrativas podem não obter resultado em termos de vendas (Gaynor 2002; Lin \& Chen 2007). A "D" manteve suas vendas e optou por não buscar novos clientes até que o cenário econômico do Brasil dê sinais de recuperação.

Quanto à otimização de custos, nos 4 casos, o resultado veio por meio de economia de escala com a expansão da fábrica e a aquisição de novos equipamentos. Esse efeito é condizente com a teoria de Prajogo \& Ahmed (2006), que destacam a adoção de tecnologias como meio importante de melhorias de desempenho. E, também, de Acs \& Audretsch 
(1990), em que a exibição de retornos crescentes é consistente com argumentos econômicos para as vantagens da escala na inovação.

Em termos não financeiros, destacam-se os prêmios conquistados pelas cervejarias "A", "C" e "D". Esses resultados são consistentes com a teoria que afirma que os ganhos com inovação não são apenas financeiros, mas também de proporção de volume anual de novos produtos, qualidade do produto, nível de novidade de produtos, aumento na participação de mercado e reputação da marca (Prajogo \& Ahmed 2006; Zeng et al. 2010; Bakar \& Ahmad 2010; Gunday et al. 2011). A inovação é um dos instrumentos fundamentais de estratégia de crescimento para entrar em novos mercados, aumentar a quota de participação em mercado existente e fornecer à empresa vantagens competitivas (Gunday et al. 2011). Os prêmios contribuem para a reputação da empresa que, consequentemente, afetam a introdução de novos produtos e o crescimento de vendas (Bakar \& Ahmad 2010).

\section{Considerações finais}

As evidências levantadas validaram em boa parte (não totalmente) o modelo proposto. De fato, observa-se que pode existir uma interação dinâmica entre inovatividade e desempenho, pois enquanto que a inovatividade influencia certos tipos de desempenho, o desempenho também se mostra capaz de influenciar a inovatividade. Ao mesmo tempo, as inovações atuam como mediadores entre os antecedentes e o desempenho das empresas. Em acréscimo, alguns dos antecedentes da inovação mostram-se capazes de afetar o desempenho, em particular o foco no cliente. Da mesma maneira, alguns tipos de inovação, em especial o lançamento de novos produtos, mostram-se capazes de influenciar desempenho e, também, de serem por ele influenciados.

Nos 4 casos analisados, o ponto forte em inovação foi a disponibilização de novos estilos de cerveja consoantes aos anseios/necessidades dos consumidores. Os resultados mostram que esse tipo de antecedente (atenção à necessidade/foco no cliente) afetou a inovação (lançamento de novos produtos), que em contrapartida também afetou os antecedentes. Novos produtos, processos e mercados exigem pessoal capacitado para atender à demanda, com crescente atenção às necessidades dos clientes, os antigos e os adquiridos recentemente.

Um bom exemplo vem da cervejaria "A". Ao realizar as modificações sugeridas pelos consumidores no produto $X$ (foco no cliente), ela não somente aumentou as vendas desse produto (desempenho financeiro), como também lançou o Y (lançamento de novo produto). $\mathrm{O}$ produto possui a mesma base do seu predecessor, porém passa por alguns processos de fabricação diferentes (melhoria de processo), que lhe conferem novo sabor. Ambos se destacam em termos de vendas. Nesse caso, ficam bem ilustradas as interconexões e circularidades entre o antecedente (foco no cliente), o desempenho financeiro (aumento de vendas) e as inovações (lançamento de um novo produto, melhoria no processo produtivo).

As interconexões entre diferentes tipos de desempenho também se mostram presentes. Nos quatro casos pesquisados, certos tipos de desempenho não financeiro (premiação em concursos; satisfação do cliente) contribuíram para incrementar o desempenho financeiro (aumento das vendas), o que demonstra mais uma relação prevista no modelo, entre o desempenho não financeiro e o financeiro.

Os resultados também sugerem que alguns tipos de inovação, para gerar impacto no desempenho, necessitam estar associados/integrados entre si. É assim que inovações de 
produtos, quando não vêm acompanhadas por inovações correspondentes em certas áreas de processo, a exemplo das áreas de apoio, podem não gerar resultados pretendidos. O caso da "B" é emblemático. Ao realizar inovações de produto e de processo, sem, no entanto, aperfeiçoar certos tipos de atividades de natureza administrava, não foi capaz de melhor usufruir dos ganhos da inovação. $\mathrm{O}$ aperfeiçoamento de processos não deve ser apenas de fabricação e distribuição, mas também de natureza gerencial, pois esses caminham juntos, em muitas circunstâncias.

A pesquisa constatou que as microcervejarias são caracterizadas pela criatividade em termos de desenvolvimento de novas receitas. No entanto, parecem enfrentar maiores dificuldades quando se trata da modernização e racionalização de certos processos de apoio, de natureza administrativa, que deveriam dar sustentação às inovações de produtos. É assim que empresas à primeira vista dotadas de criatividade produtiva, nem sempre mostram-se capazes de usufruir dessa vantagem, pois não investem em inovações nas áreas de apoio.

Embora o modelo proposto tenha se mostrado adequado para constatações e análises de muitas das dimensões do fenômeno de interesse, algumas de suas categorias de análise não se mostraram particularmente úteis para os casos em questão. Um exemplo seria as redes de parceria e cooperação, julgadas importantes por diferentes autores (Hult et al. 2004; Vale 2006) e inseridas entre os antecedentes da inovação. A pesquisa mostrou que são praticamente inexistentes. Isso poderia ser considerado um dos pontos de vulnerabilidade dessas empresas no mercado, sugerindo a necessidade de maior foco nesse aspecto.

Alguns tipos de antecedentes da inovação nem sempre garantiram, nos casos estudados, o bom desempenho da empresa. Ao mesmo tempo, a inovatividade, formada pelos antecedentes da inovação e a inovação propriamente dita, demonstrou ser capaz de afetar positivamente apenas algumas categorias de desempenho, mas não o desempenho financeiro de todas as empresas. Quando se tratou de construtos financeiros (vendas e custos), apenas em 2 casos a inovatividade afetou positivamente o desempenho. Nos outros dois, o indicador crescimento de vendas manteve-se estável. Estabilidade nas vendas de uma empresa, quando as demais demonstram crescimento, sugere, a princípio, deficiência da primeira. Isso poderia ser considerado uma limitação do modelo proposto, visto que todas as empresas citadas demonstram, de uma maneira ou de outra, capacidade de inovação (inovatividade). Uma hipótese alternativa, não considerada no estudo presente, seria a existência de uma defasagem temporal entre, por um lado, a implementação de iniciativas de inovatividade e, por outro, os momentos em que são colhidos os frutos desse processo, em termos de desempenho. Talvez eles não sejam, exatamente, sincronizados. Assim, certos resultados financeiros da inovatividade poderiam se fazer notar apenas algum tempo depois de suas implementações. Isso exigiria novas pesquisas, capazes de identificar em que condições e momentos a capacidade de inovação da empresa poderia de fato se traduzir em incremento real de vendas, de redução de custos e de outros indicadores de interesse.

O fato desse estudo não ter trabalhado com certas variáveis de desempenho, como lucratividade e outras eventualmente de interesse, gerou algum inconveniente. Variáveis desse tipo fizeram falta, especialmente durante a avaliação do desempenho da empresa "D", que optou por não investir em aumentar a produção no último ano e consequentemente não ampliou suas vendas. Porém, a empresa demonstrou ter substituído os clientes menores pelo atendimento às grandes redes de supermercado, o que pode ter gerado melhorias em termos de lucro. 
A pesquisa também não chegou a avaliar o custo benefício das inovações, em especial o retorno dos investimentos em expansão. O impacto real deste movimento estratégico não foi avaliado pelas empresas pesquisadas. Devido aos elevados custos da inovação e as limitações de recursos que enfrentam as PMEs, este movimento incorre em um alto risco para as firmas. Ao mesmo tempo, pouca ênfase na inovação também traz riscos, dado o ambiente de grande competição. As PMEs realmente precisam recolher informações suficientes sobre a demanda do mercado, a tendência para os seus produtos, os concorrentes e as fontes de inovação antes de tomar qualquer decisão (Rosli \& Sidek 2013).

Pesquisas futuras poderão contribuir para elucidar problemas aqui expostos e, também, para ampliar os conhecimentos na área. Sugerem-se, em particular, pesquisas comparativas mais extensas, envolvendo diferentes regiões/estados; ou estudos longitudinais em cervejarias que já foram microempresas e atingiram patamares superiores; ou, ainda, estudos sobre inovatividade e desempenho, incorporando, também, outros construtos de interesse, a exemplo do papel das redes sociais.

\section{Referências}

Acs, Zoltan J., \& David B. Audretsch. 1990. Innovation and small firms. Innovation measurement and policies.

Artz, Kendall W., Patricia M. Norman, Donald E. Hatfield, \& Laura B. Cardinal. 2010. A longitudinal study of the impact of $R \& D$, patents, and product innovation on firm performance. Journal of Product Innovation Management, 27, 725-740.

Associação Brasileira da Indústria da Cerveja. 2018. Dados do setor cervejeiro nacional. Recuperado a partir de http://www.cervbrasil.org.br/novo_site/dados-do-setor/

Bakar, Lily Julienti Abu, \& Hartini Ahmad. 2010. Assessing the Relationship between Firm Resources and Product Innovation Performance. Business Process Management Journal, 16(3), 420-435.

Brasil, Marcus Vinicius de Oliveira, Cláudio André Gondim Nogueira, \& Sérgio Henrique Arruda Cavalcante Forte. 2011. Schumpeter e o Desenvolvimento Tecnológico: uma visão aplicada às Pequenas e Médias Empresas (PMEs). 13(29), $38-62$.

Calantone, Roger J., Tamer S. Cavusgil, \& Yushan Zhao. 2001. Learning orientation, firm innovation capability, and firm performance. Industrial Marketing Management, 31(6), 515-524.

Damanpour, Fariborz. 1991. Organizational innovation: a meta-analysis of effects of determinants and M...: EBSCOhost. Academy of Management Journal, 34(3), 555590.

Ferreira, Rubens Hermógenes, Maria Celeste R Lobo Vasconcelos, Valéria Maria Martins Judice, \& Jorge Tadeu de Ramos Neves. 2011. Inovação na fabricação de cervejas especiais na região de Belo Horizonte. Perspectivas em Ciência da Informação, (164), 171-191.

Gaynor, Gerard. H. 2002. Innovation by Design: What it takes to keep your company on the cutting edge. American management association.

Garrigós-Simón, Fernando J., \& Daniel Palacios Marqués. 2004. Competitive Strategies and Firm Performance. Management Research: Journal of the Iberoamerican Academy of Management, 2(3), 251-269. 
Gunday, Gurhan, Gunduz Ulusoy, Kemal Kilic, \& Lutfihak Alpkan. 2011. Effects of innovation types on firm performance. International Journal of Production Economics, 133(2), 662-676.

Hult, G. Tomas M., Robert F. Hurley, \& Gary A. Knight. 2004. Innovativeness: Its antecedents and impact on business performance. Industrial Marketing Management, 33(5), 429-438.

Kalnin, Joanir Luís, Nelson Casarotto Filho, João Ernesto E. Castro. 2002. Análise estratégica para implantação de empresas de pequeno porte: Cervejarias artesanais. Revista Produção, 2 (1), 1-11.

Knowles, Chris, Eric Hansen, \& Steven R. Shook. 2008. Assessing innovativeness in the North American softwood sawmilling industry using three methods. Canadian Journal of Forest Research, 38(2), 363-375.

Lee, Ryeowon, Jong-Ho Lee, \& Tony C. Garrett. 2017. Synergy effects of innovation on firm performance. Journal of Business Research, 10.

Lima, Gustavo Barbieri, Orlando Nastri Neto, \& Dirceu Tornavoi de Carvalho. 2013. O papel e a importância das mídias sociais no composto de comunicação de pequenas empresas: um estudo de caso em microcervejaria. Revista de Administração, Contabilidade e Economia, 4 (1), 01-16.

Lin, Carol Yeh-Yun, \& Mavis Yi-Ching Chen. 2007. Does Innovation Lead to Performance? An Empirical Study of SMEs in Taiwan, Management Research News, 30 (2), 115-132.

Lin, Chien-Huang, Ching-Huai Peng, \& Danny T. Kao. 2008. The innovativeness effect of market orientation and learning orientation on business performance. International Journal of Manpower, 29(8), 752-772.

Ministério da Agricultura, Pecuária e Abastecimento. 2019. Anuário da cerveja no Brasil 2018: Crescimento e Inovação. Recuperado a partir de http://www.agricultura.gov.br/assuntos/inspecao/produtos-vegetal/pastapublicacoes-DIPOV/anuario-da-cerveja-no-brasil-2018

Nery, Marcus Vinícius Mathias. 2017. A construção de significados por meio de rituais: um estudo do consumo de cervejas artesanais. (Dissertação de mestrado). Pontifícia Universidade Católica de Minas Gerais.

Prajogo, Daniel I., \& Pervaiz K. Ahmed. 2006. Relationships between innovation stimulus, innovation capacity, and innovation performance. R\&D Management, 36, 499-515.

Quandt, Carlos Olavo, Cicero Aparecido Bezerra, \& Alex Antônio Ferraresi. 2013. 10 dimensões da inovatividade e seus impactos no desempenho inovador. Encontro da Associação Nacional de Pós-Graduação e Pesquisa em Administração, 1-16.

Richard, Pierre J., Timothy M. Devinney, George S. Yip, \& Gerry Johnson. 2009. Measuring organizational performance: Towards methodological best practice. Journal of Management, 35(3), 718-804.

Robertson, Paul L.; G. L. Casali; \& David Jacobson. 2012. Managing open incremental process innovation: absorptive capacity and distributed learning. Research Policy, 41, 822-832.

Rosli, M. Mohd, \& Syamsuriana Sidek. 2013. The Impact of Innovation on the Performance of Small and Medium Manufacturing Enterprises: Evidence from Malaysia. Journal of Innovation Management in Small \& Medium Enterprise, 1-16. 
Rubera, Gaia, \& Ahmet H. Kirca. 2012. Firm Innovativeness and Its Performance Outcomes: A Meta-Analytic Review and Theoretical Integration. Journal of Marketing, 76(3), 130-147.

Schumpeter, Joseph Alois. 1988. Teoria do desenvolvimento econômico: uma investigação sobre lucros, capital, crédito, juro e o ciclo econômico. Traduzido por Maria Sílvia Possas. (3a ed.). São Paulo: Nova Cultural. (Obra original publicada em 1911).

Slater, Stanley F., \& John C. Narver. 1995. Market Orientation and Learning Organization. Journal of Marketing.

Stefenon, Rafael. 2012. Vantagens competitivas sustentáveis na indústria cervejeira: o caso das cervejas especiais. Revista Capital Científico. 10 (1), 1-16.

Tidd, Joe, \& John Bessant. 2008. Gestão da Inovação. ( $3^{\mathrm{a}}$ ed.). Porto Alegre: Bookman.

Vale, Gláucia Maria Vasconcellos. 2006. Laços como ativos territoriais: análise das aglomerações produtivas na perspectiva do capital social. (Tese de doutorado). Universidade Federal de Lavras.

Vasconcelos, Yuri. 2017. Inovações Cervejeiras. Pesquisa FAPESP 251, 18-25.

Veit, Mara R. (2014). Desempenho das micro e pequenas empresas: o perfil do potencial empreendedor, a estratégia da inovação e da inovatividade. (Tese de doutorado). Universidade FUMEC.

Zeng, S. X., X. M. Xie, \& C. M. Tam. 2010. Relationship between Cooperation Networks and Innovation Performance of SMEs. Technovation, 30, 181-194. 